\title{
Nonsense Mutation Causing Steroid 21-Hydroxylase Deficiency
}

\author{
Hadas Globerman, Mounira Amor, Keith L. Parker," Maria I. New, and Perrin C. White \\ Division of Pediatric Endocrinology, Cornell University Medical College, New York, New York 10021; and ${ }^{*}$ Howard Hughes Medical \\ Institute and Department of Medicine, Duke University Medical Center, Durham, North Carolina 27710
}

\begin{abstract}
We determined the sequence of a mutant CYP21B gene isolated from a patient with the severe, "salt-wasting" form of congenital adrenal hyperplasia due to steroid 21-hydroxylase deficiency. Codon 318 in this gene is changed from CAG, encoding glutamine, to TAG, a nonsense codon. This is predicted to result in a completely nonfunctional enzyme due to premature termination of translation. In addition, when the cloned mutant gene was transfected into mouse $Y 1$ adrenal cells, the resulting mRNA levels were decreased compared with transfected normal CYP21B genes. This mutation was carried by 3 of 20 unrelated patients with 21-hydroxylase deficiency alleles as determined by hybridization with a specific oligonucleotide probe. This mutation is also seen in the normal CYP21A pseudogene, so that its presence in the abnormal $C Y P 21 B$ gene may be the result of a gene conversion event.
\end{abstract}

\section{Introduction}

Human 21-hydroxylase deficiency is the leading cause of impaired cortisol synthesis in congenital adrenal hyperplasia (1). The incidence of classical 21-hydroxylase deficiency is 1 in 5-10,000 live births; a milder "nonclassical" form of the disease occurs in $0.3 \%$ of Caucasians and in $1-3 \%$ of European Jews. Deficient cortisol synthesis causes increased secretion of corticotropin (ACTH), resulting in hyperplasia of the adrenal cortex, excessive production of androgens, and consequent virilization. In two-thirds of patients with the classical disease, 21-hydroxylase deficiency also impairs aldosterone synthesis, resulting in urinary "salt wasting" with the risk of shock and death in the neonatal period. Steroid 21-hydroxylase deficiency is inherited as an autosomal recessive trait linked to the HLA MHC on chromosome 6. This disorder is caused by a defect in the structural gene that encodes an adrenal microsomal cytochrome P-450, which is specific for steroid 21-hydroxylation (P450c21) (2). There are two 21-hydroxylase genes, $C Y P 21 A$ and $B$ (also termed $C A 21 H A$ and $B$, or $P 450 C 21 A$ and $B)$, respectively, adjacent to the $C 4 A$ and $C 4 B$ genes, which encode the fourth component of serum complement $(3,4)$ (Fig. 1). Individuals with homozygous deletions of $C Y P 21 A$ demonstrate normal cortisol synthesizing capacity,

Address all correspondence to Dr. Perrin C. White, Laboratory of Molecular Endocrinology, Department of Pediatrics, Rm. N236, Cornell University Medical College, 525 East 68th Street, New York, NY 10021.

Received for publication 10 November 1987 and in revised form 2 February 1988.

J. Clin. Invest.

(c) The American Society for Clinical Investigation, Inc.

0021-9738/88/07/0139/06 \$2.00

Volume 82, July 1988, 139-144 whereas homozygous deletion of $C Y P 21 B$ causes 21-hydroxylase deficiency. Nucleotide sequence analysis has confirmed that the active enzyme is encoded by the $C Y P 21 B$ gene. The $C Y P 21 A$ gene is $97 \%$ homologous to the $B$ gene, but it is rendered nonfunctional by several critical mutations in the coding region, including an 8-bp deletion in exon 3, a 1-bp insertion in exon 7 , and a nonsense mutation in exon $8(5,6)$ (Fig. 2).

Deletions of CYP21B account for about one-fourth of classical 21-hydroxylase deficiency alleles $(7,8)$. These alleles were presumably generated by unequal crossing-over during meiosis due to the presence of the adjacent $C Y P 21 A$ pseudogene. Two nondeleted mutant $C Y P 21 B$ alleles have been characterized thus far. One (9) contains an amino acid substitution (Ser-269 to Thr) of unknown functional significance and unknown frequency; the other (10) carries a nonconservative amino acid substitution (Ile-172 to Asn) and is found in about $15 \%$ of patients. This latter mutation is normally present in the CYP21A pseudogene, which suggests that it may have been transferred to the $C Y P 21 B$ gene by a smaller recombinational event, termed a "gene conversion." This paper presents further evidence that gene conversion events are a frequent cause of 21-hydroxylase deficiency alleles: a nonsense mutation normally present in $C Y P 21 A$ was detected in the $C Y P 21 B$ genes of several patients. In addition to affecting protein synthesis, this mutation may adversely affect mRNA levels.

\section{Methods}

Enzymes and related reagents were purchased from International Biotechnologies, Inc. (New Haven, CT) and were used according to the manufacturer's instructions.

Southern blot hybridization. DNA samples were prepared as described (11) from peripheral blood leukocytes of 20 unrelated patients with classical 21-hydroxylase deficiency (Table I). Samples were digested with restriction endonuclease Taq I, subjected to electrophoresis in agarose, and blotted (12) to MSI nylon membranes (Fisher Scientific Co., Springfield, NJ). Blots were hybridized as described (7) to radioactively labeled pC21/3c, which contains a nearly full-length cDNA clone encoding human steroid 21-hydroxylase (6). Diminished intensity of the 3.7-kb Taq I band in certain patients, which suggested heterozygous deletion of the $C Y P 21 B$ gene, was confirmed by scanning densitometry and by analysis with additional restriction endonucleases. Many of these patients were previously studied in this manner (10).

Construction of a partial genomic library. A patient with severe, salt-wasting 21-hydroxylase deficiency was selected who appeared to have a heterozygous deletion of CYP21B on the basis of Southern blot hybridization. Any 21-hydroxylase enzyme remaining in this patient would have to be encoded by the single nondeleted CYP21B gene. DNA from this patient was digested with Bam $\mathrm{HI}$ and was size fractionated by electrophoresis in agarose. CYP21A and $B$ genes are both carried on 14-kb Bam HI fragments (Fig. $1 b$ ); thus, fractions containing DNA of about this size were electroeluted from the gel (13) and assayed for the presence of the CYP21 genes by Southern blotting. Appropriate fractions were ligated to digested $\lambda E$ MBL3 arms (Strata- 


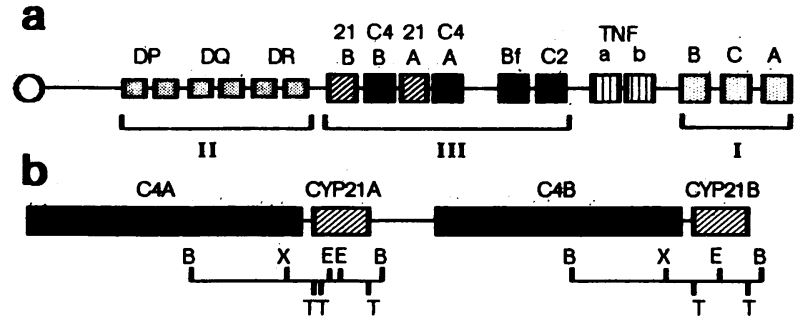

Figure 1. Cloning of CYP21 genes encoding P450c21. (a) The HLA complex on the short arm of chromosome 6 . The centromere is indicated by the circle at left. HLA Class II, III, and I genes are grouped. Class I and II genes encode transplantation antigens; there are more Class II genes than are diagrammed here. TNF $a$ and $b$ encode tumor necrosis factor alpha and beta. $C 2, B f, C 4 A$ and $C 4 B$ encode serum complement components; $21 A$ and $21 B$ are the $C Y P 21$ genes. (b) Strategy for cloning of the CYP21 genes. The relative sizes and locations of the $C 4$ and $C Y P 21$ genes are shown. The genes are all transcribed left to right. Relevant restriction sites are indicated: $B$, Bam HI; $E$, Eco RI; $T$, Taq I; $X$, Xho I.

gene, La Jolla, CA) (14). The ligated material was packaged (using extracts obtained from Stratagene) into bacteriophage lambda particles (15), which were then used to infect Escherichia coli strain C600. The library was plated at a density of about 20,000 plaques/150-mm plate.

Isolation of a mutant CYP21B gene. Nitrocellulose filter replicas of the library were screened with radioactively labeled $\mathrm{pC} 21 / 3 \mathrm{c}$ as described (16). Clones carrying $C Y P 21$ genes were identified by autoradiography, purified by replating, and grown in large cultures. Bacteriophage DNA was prepared (17); clones were identified as carrying either the $C Y P 21 A$ or $B$ genes by the presence of a $3.2-$ or $3.7-\mathrm{kb}$ Taq I band, respectively, on blot hybridization with labeled $\mathrm{pC} 21 / 3 \mathrm{c}$ plasmid (3).

DNA sequence analysis. The 3.7-kb Taq I fragment from a cloned $C Y P 21 B$ gene was subcloned into the Acc I site of the bacteriophage M13mp8 (18). The recombinant phage were used to transform $E$. coli MV1190, and clones with the insert in each orientation were selected.

SILENT MUTATION AMINOACIDSUBSTITUTION NONSENSE OR FRAMESHIFT

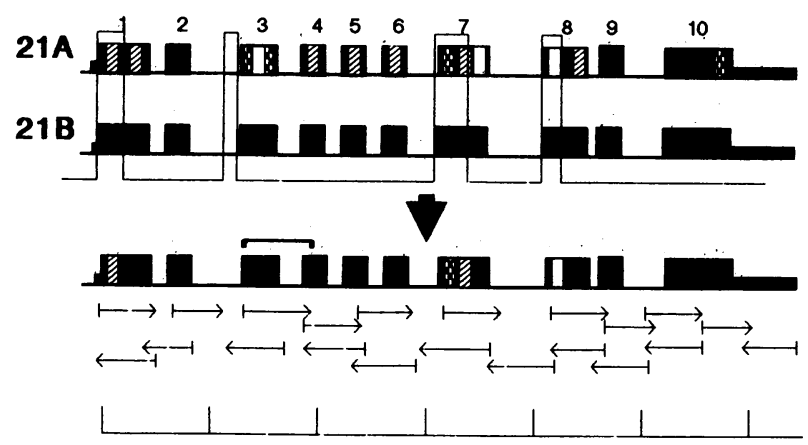

Figure 2. Organization of the $C Y P 21$ genes. Numbered bars represent sequences expressed in mRNA, or exons, while the spaces between bars correspond to introns. The shorter bars at the ends of the diagram represent $5^{\prime}$ and $3^{\prime}$ untranslated regions. Types of mutations within the CYP21A pseudogene are indicated by the shading of exons as noted. A line represents locations of possible gene conversions that have resulted in the mutant $C Y P 21 B$ gene, which is diagrammed below. Arrows at the bottom of the diagram indicate positions and orientations of primers used for sequencing. The bracket indicates the fragment used in the RNase protection assay presented in Fig. 5.
Sequence analysis was performed by the chain termination method (19) using ${ }^{35} \mathrm{~S}-\mathrm{dATP}$ as described (20) except that reactions were carried out at $37^{\circ} \mathrm{C}$. In addition to the $\mathrm{M} 13$ universal sequencing primer (International Biotechnologies, Inc.), specific 17-bp oligonucleotide primers (synthesized by the Department of Microbiology at Cornell University Medical College) were used, which corresponded to the normal $C Y P 21 B$ sequence $(5,6) .10$ primers were used in each direction to cover the 3.1-kb length of the gene (Fig. 2). A previously characterized normal $C Y P 21 B$ gene was also analyzed with each primer to eliminate the possibility of artifacts arising from the use of specific primers.

Hybridization studies using oligonucleotides. DNA samples from 20 patients were digested with Taq I and subjected to electrophoresis in 3-mm-thick; horizontal $0.8 \%$ agarose gels. Gels were alkalinized, neutralized, and dried as described (21).

Oligonucleotides were end labeled using $\left[{ }^{32} \mathrm{P}\right] \mathrm{ATP}$ and polynucleotide kinase to a specific activity of $10^{9} \mathrm{dpm} / \mu \mathrm{g}$, and purified by electrophoresis in polyacrylamide. Gels were hybridized overnight at $53^{\circ} \mathrm{C}$ with labeled oligonucleotides $\left(4 \times 10^{6} \mathrm{dpm} / \mathrm{ml}\right)$ in $0.9 \mathrm{M} \mathrm{NaCl}, 90 \mathrm{mM}$ $\mathrm{Na}$ citrate (pH 7), $0.5 \% \mathrm{SDS}$, and $0.2 \mathrm{mg} / \mathrm{ml}$ salmon sperm DNA. Gels were washed in $3 \mathrm{M}$ tetramethylammonium chloride as described (22, 23 ), with the modification that the first three washes were at room temperature and the fourth was at $63^{\circ} \mathrm{C}$ for $10 \mathrm{~min}$.

Transfection into $Y 1$ cells. Cultured Y1 mouse adrenocortical tumor cells were cotransfected as described (24) with pSV2-neo (2 $\mu \mathrm{g})$ and plasmids carrying normal or mutant human $C Y P 21 B$ genes $(15$ $\mu \mathrm{g}$ ). After selection with G418 (Gibco Laboratories, Grand Island, NY) at $400 \mu \mathrm{g} / \mathrm{ml}$, resistant clones were pooled and maintained in selective medium.

Analysis of expression of transfected CYP21B genes. The expression of the transfected genes was assessed by RNase protection assays as described (25). The probe consisted of a 316-bp Pst I-Eco RI fragment of the normal human $C Y P 21 B$ gene, which contained the entire third exon ( $155 \mathrm{bp}$ ), the third intron, and $48 \mathrm{bp}$ from the fourth exon, cloned into pIBI31. A radioactively labeled antisense transcript was synthesized using T7 polymerase (Boehringer Mannheim Diagnostics, Inc., Indianapolis, IN) and [ ${ }^{32}$ P]UTP. Total cellular RNA that was prepared (26) from a human adrenal gland or from pools of transfectants was hybridized to the radiolabeled probe for $12 \mathrm{~h}$ at $50^{\circ} \mathrm{C}$ under the described conditions. Single-stranded RNA was then digested with a mixture of RNase $A$ and RNase $T_{1}$. The protected fragments were resolved by electrophoresis on an $8 \mathrm{M}$ urea, $6 \%$ polyacrylamide gel, and the dried gel was autoradiographed.

\section{Results}

A nonsense mutation causing 21-hydroxylase deficiency. A partial genomic library of 200,000 clones was prepared from DNA from a patient with salt-wasting 21-hydroxylase deficiency. Seven clones were isolated that carried $C Y P 21$ genes, of which one carried the single nondeleted CYP21B gene.

Several mutations were observed in this gene (Fig. 3). These included a 3-bp insertion between codons 9 and 10 in exon 1 (which inserts an extra leucine residue into a series of four successive leucines), a silent third-position change in codon 248 (numbering of codons does not include the 3-bp insert) from CTC to CT $G$, and a change in codon 281 from $G \mathrm{TG}$, encoding valine, to $T \mathrm{TG}$, leucine. A cluster of several mutations was also observed within the second intron (intron b). Most importantly, codon 318 in exon 8 is changed from CAG, encoding glutamine, to $T A G$, which is a nonsense codon. This is predicted to cause premature termination of translation of the mRNA before the conserved "heme-binding" region of the $\mathrm{P} 450$ polypeptide, which results in a completely nonfunctional enzyme. All of these mutations are 


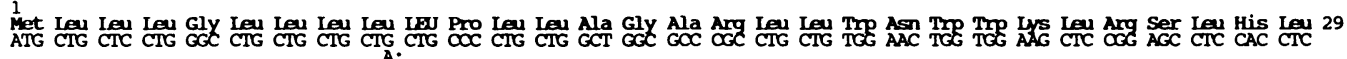
A:

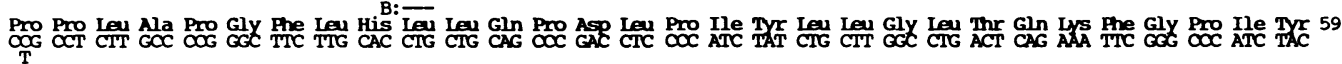

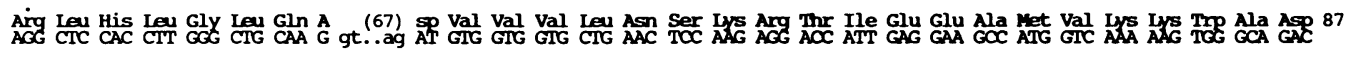
Phe Ala Gly Arg Pro Glu Pro Ieu Thr T (97)

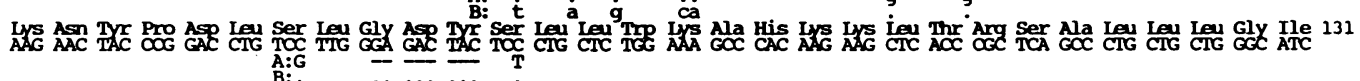

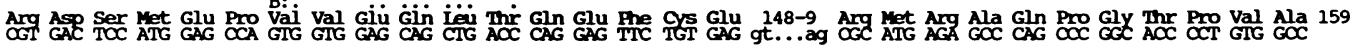

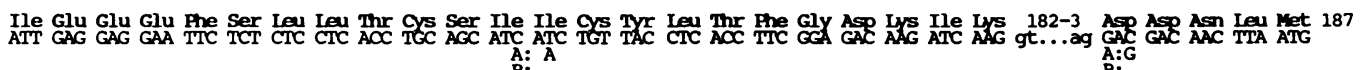

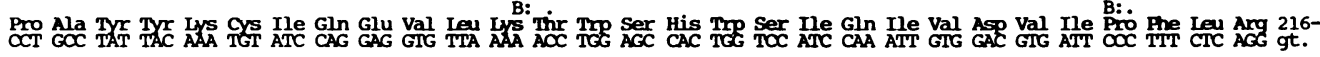

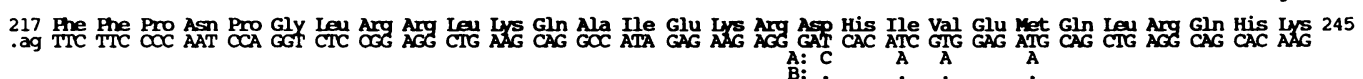

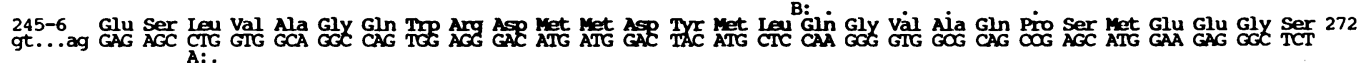

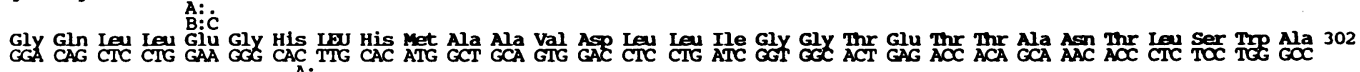
$A: \dot{G}$

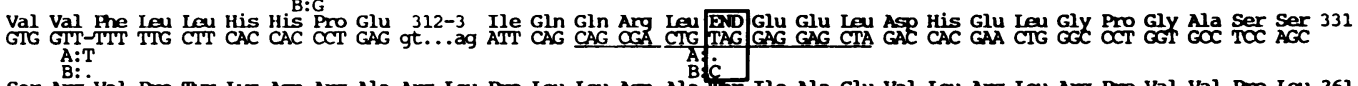

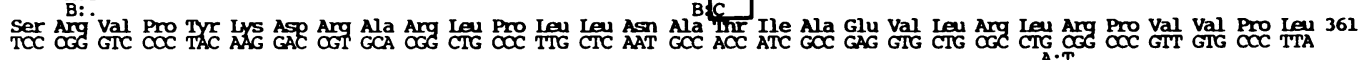

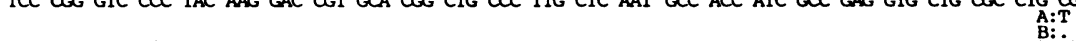

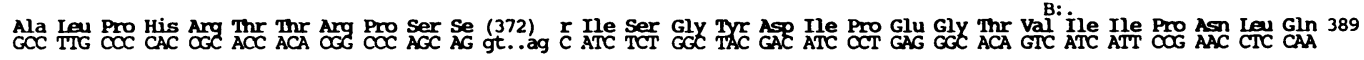

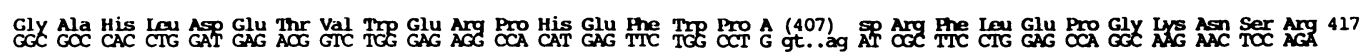

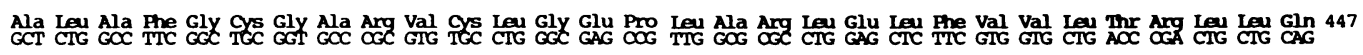

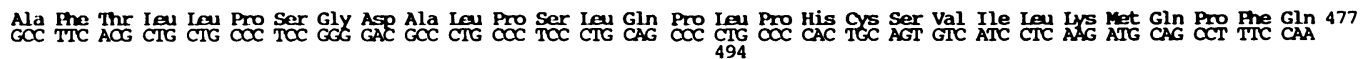
Val Ang leu Gln Pro Ang Gly met Gly Ala His Ser Pro Gly Glin Asn Gin End
Figure 3. Sequence of the mutant CYP21B gene. Only coding sequences and intron junctions are shown; codons are numbered at the introns. Numbering does not include the 3-bp insert in exon 1 ; numbers in parentheses indicate an intron that is located within a codon. Where the sequence differs from sequences of the normal CYP21A pseudogene or the $C Y P 21 B$ gene, those sequences are also displayed and are labeled $A$ : and $B$ : (dots signify no difference between the mutant $C Y P 21 B$ gene and the normal $A$ or $B$ gene, as indicated).

Dashes represent missing bases. The critical mutation in codon 318 is boxed; the location of the corresponding oligonucleotide is underlined. present in the normal $C Y P 21 A$ pseudogene. However, other mutations present in the $C Y P 21 A$ gene were not observed in this mutant $C Y P 21 B$ gene.

Oligonucleotide hybridization studies of patients. A 21-mer oligonucleotide corresponding to codons 315-321 of the mutant gene on the antisense strand (5'-TAG CTC CTC CT $A$ CAG TCG CTG-3') was hybridized to Taq I digests of DNA samples from patients with 21-hydroxylase deficiency (Fig. 4). Because this mutation is normally present in the CYP21A pseudogene, it was expected that DNA from normal individuals would contain a hybridizing Taq I fragment of $3.2 \mathrm{~kb}$, corresponding to the $C Y P 21 A$ genes, but no signal at $3.7 \mathrm{~kb}$, which is the size of the Taq I fragments from the CYP21B genes. In fact, 19 of 20 samples from patients contained a

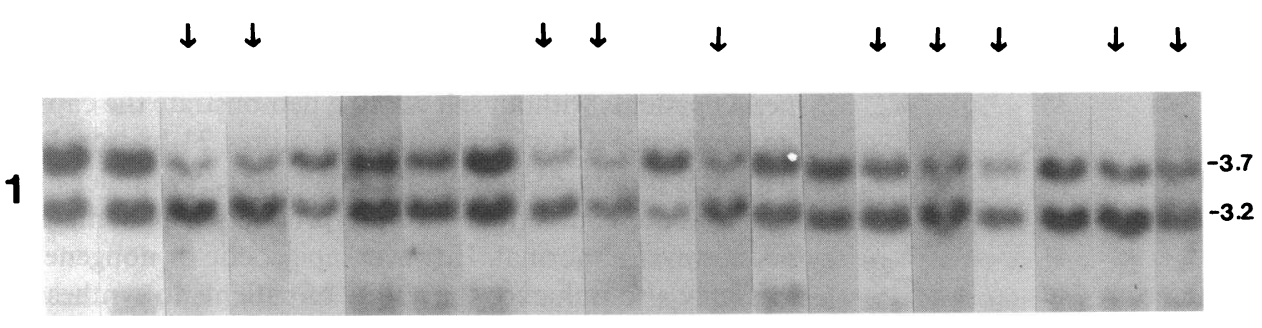

A

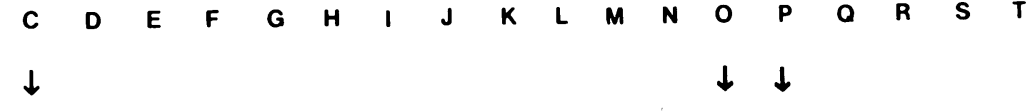

2

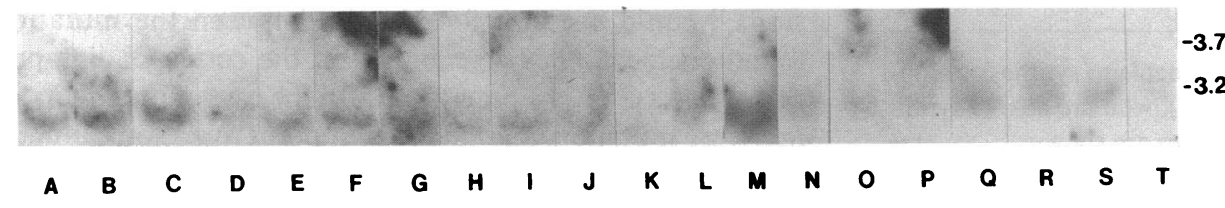

Figure 4. Hybridization to Taq I digests of DNA samples from 20 patients with classical 21-hydroxylase deficiency. Numbers to the right of each line indicate fragment sizes in kilobases. (1) Southern blot using radioactively labeled $\mathrm{pC} 21 / 3 \mathrm{c}$, a human $\mathrm{cDNA}$ clone, as a probe. Arrows indicate patients with presumed heterozygous deletions of $C Y P 21 B$. (2) Hybridization with an oligonucleotide probe that corresponds to the mutation in codon 318. All patients carry a $3.2-\mathrm{kb}$ Taq I fragment that hybridizes with each probe and corresponds to the CYP21A pseudogenes that normally carry this mutation. Three patients (arrows) carry a 3.7-kb Taq I fragment that also hybridizes with the probe, presumably signifying a mutant $C Y P 21 B$ gene. The mutant gene was first isolated from patient $\mathrm{C}$. 
hybridizing band of $3.2 \mathrm{~kb}$, while 3 of 20 patients (patients $C$, $\mathrm{O}$, and $\mathrm{P}$; the mutant gene was isolated from DNA of patient C) carried a 3.7-kb Taq I fragment that hybridized with this probe. These three patients who have CYP21B genes with the codon 318 mutation suffer from the salt-wasting form of 21hydroxylase deficiency. They all have a heterozygous deletion of CYP21B. Two of them carry the HLA-Bw47;DR7 haplotype known to carry such a deletion; no other HLA-B antigen is shared by any of these patients (Table I).

Expression of human CYP21B genes in transfected $Y 1$ cells. To determine if mRNA transcribed from this mutant gene was present in normal amounts, plasmids carrying the normal and mutant $C Y P 21 B$ genes were transfected into Y1 mouse adrenocortical tumor cells. Pools of transfectant clones were prepared to minimize the effect of clonal variation on 21-hydroxylase (CYP21B) expression. RNase protection assays (which are more sensitive than Northern blots) were used to determine steady-state mRNA levels in transfectants. The results (Fig. 5) show that Y1 cells transfected with either the normal or the mutant gene contain CYP21B transcripts, as documented by their protection of a 155-nucleotide fragment (corresponding to all of exon 3) that is identical in size to the fragment protected by authentic human adrenal mRNA. In addition to the protected fragment of 155 nucleotides, these samples also contained a 48-nucleotide fragment protected by sequences contained in exon 4 , which was poorly resolved under the gel conditions used (not shown). As previously noted (24), parental Y1 cells do not express their own 21-hydroxylase genes. This technique is only semiquantitative, as evidenced by the substantial variation in mRNA levels in dif-

Table I. Patients Used in Hybridization Studies Shown in Fig. 4

\begin{tabular}{llrrrr}
\hline & & \multicolumn{4}{c}{ HLA } \\
\cline { 3 - 6 } Patient & Diagnosis & B & DR & B & DR \\
\hline A & SV & 18 & 6 & 44 & 5 \\
B & SW & 49 & 8 & 44 & 6 \\
C* & SW & 47 & 7 & 57 & 7 \\
D & SW & 39 & 2 & 47 & 7 \\
E & SW & 52 & 2 & 52 & 2 \\
F & SW & 39 & 9 & 51 & 5 \\
G & SW & 14 & 1 & 35 & 5 \\
H & SW & 44 & 4 & 51 & 4 \\
I & SW & 22 & 4 & 39 & 9 \\
J & SW & 35 & 5 & 47 & 7 \\
K & SW & 8 & 3 & 35 & 4 \\
L & SW & 44 & 7 & 47 & 7 \\
M & SW & 7 & 10 & 7 & 10 \\
N & SV & 7 & 1 & 40 & 1 \\
O* & SW & 7 & 2 & 47 & 7 \\
P* & SW & 35 & 5 & 40 & 7 \\
Q & SV & 51 & 6 & 44 & 1 \\
R & SW & 45 & 5 & 49 & 6 \\
S & SV & 44 & 7 & 51 & 4 \\
T & SW & 18 & 1 & 18 & 5 \\
& & & & & \\
\hline & & & & &
\end{tabular}

Patients are "salt-wasters" (SW), who are unable to synthesize aldosterone normally, or "simple virilizers" (SV), who are able to synthesize aldosterone. HLA-B and -DR haplotypes are shown.

* Patients with a mutation in codon 318.

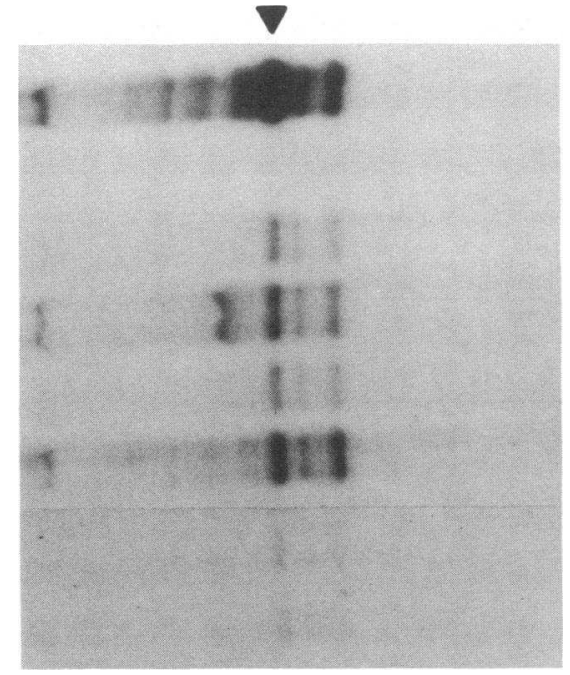

ADRENAL

YI

NORMAL-1

NORMAL-2

NORMAL-3

NORMAL-4

MUTANT - 1

MUTANT - 2

Figure 5. Levels of 21-hydroxylase (CYP21B) mRNA in the normal human adrenal gland, in parental Y1 adrenocortical cells, and in Y1 cells transfected with cloned normal or mutant $C Y P 21 B$ genes. The RNase protection assays were performed using 2 (human adrenal gland) or $20 \mu \mathrm{g}$ (all other lanes) of each RNA. The position of the 155-nucleotide fragment that is protected by sequences from the third exon is indicated.

ferent pools of cells transfected with the normal CYP21B gene. Nevertheless, 21-hydroxylase mRNA levels in cells transfected with the codon 318 mutant appear to be markedly lower than the levels seen with transfection of the normal human $C Y P 21 B$ gene.

\section{Discussion}

These data identify a genetic basis for certain cases of the severe, salt-wasting form of 21-hydroxylase deficiency. Salt wasting results from impaired synthesis not only of cortisol, but also of aldosterone, and it is to be expected that this form of the disease should be caused by a (nearly) complete absence of the 21-hydroxylase enzyme. It was previously known that the genetic basis for salt wasting in a few patients was a total deletion of the CYP21B gene $(2,8)$. We have now shown in three patients, all of whom also have a heterozygous deletion of $C Y P 21 B$, that salt-wasting disease also results from a nonsense mutation that precludes synthesis of the P450c21 enzyme. As patients without salt wasting demonstrate the capacity to synthesize aldosterone, which requires 21-hydroxylase activity, it is presumed that these individuals carry milder mutations that are compatible with the production of some enzyme, however abnormal. However, epigenetic or nongenetic factors may also influence the ability of patients to synthesize aldosterone (27).

The results also suggest a mechanism whereby the mutations in the sequenced $C Y P 21 B$ gene have occurred. Relatively small nonreciprocal recombination events, or "gene conversions," could account for identity between the mutations found on the $C Y P 21 B$ gene and on the corresponding positions on the $C Y P 21 A$ pseudogene. In the case of the codon 318 nonsense mutation, an independent point mutation cannot be ruled out. The precise borders of the putative gene conversion 
cannot be firmly established because of the high degree of homology between the $C Y P 21 A$ and $B$ genes; the maximum size, based on the absence of other mutations from $C Y P 21 A$, would extend from the $3^{\prime}$ end of intron $\mathrm{g}$ to codon 355 in exon 8. The two other possible gene conversions in exons of this mutant gene (the 3-bp insertion in exon 1 and the mutations in exon 7 affecting codons 248 and 281) and the cluster of mutations in intron b are separated in CYP21 A from the codon 318 mutation by intervening mutations that are not present in the mutant CYP21B gene. Thus, if they are gene conversions, they must have been transferred to $C Y P 21 B$ in independent events. The mutations in intron $b$ and the extra leucine resulting from the 3-bp insertion in exon 1 have no obvious functional signifcance and might exist as polymorphisms of the CYP21B gene in the normal population. The extra leucine is present in P450c21 of mice (28) and cattle (29) and has been documented in a cloned normal CYP21B gene (9). The codon 281 mutation is associated with a very common nonclassical 21 -hydroxylase deficiency allele (30) and therefore heterozygous carriers of this mutation should also occur frequently in the general population. Thus, the existence of these multiple gene conversions in one mutant $C Y P 21 B$ gene is not surprising.

In addition to containing a mutation that prevents synthesis of a functional protein, the steady-state levels of mRNA transcribed from this mutant gene in Y1 adrenal cells are substantially decreased from the levels observed when normal $C Y P 21 B$ genes are transfected. This finding might be explained by a difference in the rate of integration of normal and mutant CYP21B genes into the Y1 cell genome or by an additional undetected mutation in the promoter region that affects transcription of the mutant gene. It is more likely that the nonsense mutation itself affects mRNA stability. This may occur because the mRNA downstream of the nonsense mutation does not carry ribosomes and may be more susceptible to nucleases. The same phenomenon has previously been noted in a nonsense mutation, which causes $\beta^{\circ}$-thalassemia (31), and in the murine 21-hydroxylase pseudogene (28). It will be necessary to assess the transcriptional activity of the transfected genes in order to definitively answer this question.

While this study has identified 3 out of 20 patients with possible gene conversions causing 21-hydroxylase deficiency, there are 10 other mutations in the CYP21A pseudogene that terminate protein synthesis or change amino acid sequences, and which therefore might result in 21-hydroxylase deficiency if they were transferred to the $C Y P 21 B$ gene. Indeed, a mutation in codon 172 which is normally found in the CYP21A gene has been documented in the $B$ genes of three patients with 21-hydroxylase deficiency (10). Thus, gene conversions might prove to be as common as deletions as a cause of 21 -hydroxylase deficiency alleles.

Humans, mice (32), and cattle (33) all have two 21-hydroxylase genes, which suggests that the duplication occurred before mammalian speciation. It has been slightly puzzling that, in mice and men, the two 21-hydroxylase genes are much more homologous to each other than they are to the corresponding gene in the other species. The high frequency of apparent gene conversions provides an explanation for this finding. It is likely that sequences from $C Y P 21 B$ may occasionally be transferred to $C Y P 21 A$ by this mechanism. It should be noted that DNA from patient $\mathrm{K}$ in this study (who has a heterozygous deletion of $C Y P 21 A$ ) yields no signal at 3.2 $\mathrm{kb}$ when probed with the oligonucleotide that corresponds to the codon 318 mutation, although the identical gel displays a strong signal at this position when probed with additional CYP21A-specific oligonucleotides (not shown). This CYP21A gene may thus have reverted to the $C Y P 21 B$ sequence in this region. Gene conversions have also been documented as a factor in the evolution of other cytochrome P450 gene families (34).

Oligonucleotide hybridization might improve prenatal diagnosis of 21-hydroxylase deficiency. At present, prenatal diagnosis is based on HLA typing of fibroblasts and measurement of hormone levels in amniotic fluid obtained by amniocentesis at about the 16th wk of gestation (35), or HLA typing can be performed by Southern blot hybridization using DNA prepared from a chorionic villus sample (36). Prenatal diagnosis using oligonucleotide probes has two potential advantages over HLA typing: it obviates the need for a DNA sample from the index case and it excludes possible misdiagnosis due to recombinations within the HLA complex. The efficiency of this approach would be improved by prior identification of the involved mutations in the parents. Southern blot analysis of several restriction digests using a 21-hydroxylase cDNA probe would be necessary to detect deletions and to rule out gene conversions involving the restriction sites used to distinguish the $C Y P 21 A$ and $C Y P 21 B$ genes.

Oligonucleotide hybridization using DNA obtained by chorionic villus biopsy would enable a diagnosis before the differentiation of the fetal external genitalia. Virilization of the external genitalia in an affected female fetus might be prevented by the administration of glucocorticoids to the mother before this critical time of development (37). To be practical, this method of prenatal diagnosis will require identification of additional mutations that cause 21-hydroxylase deficiency.

\section{Acknowledgments}

We thank Alena Vitek for technical assistance and Dr. R. Bruce Wallace for helpful discussions. HLA genotyping of patients was performed by Dr. B. Dupont. Oligonucleotides were synthesized by the Department of Microbiology, Cornell University Medical College.

H. Globerman is the recipient of a Charles H. Revson Foundation fellowship in biomedical research, and her work has been aided by a Daland Fellowship from the American Philosophical Society. M. Amor is supported by a fellowship from Centre National de la Research Scientifique (France). This work is supported by National Institutes of Health grants DK-37867 (P. C. White), CA-22507 (B. Dupont), and HD-00072 (M. I. New), and by the Horace Goldsmith Foundation. P. C. White is an Andrew W. Mellon Teacher-Scientist.

\section{References}

1. White, P. C., M. I. New, and B. Dupont. 1987. Congenital adrenal hyperplasia. $N$. Engl. J. Med. 316:1519-1524, 1580-1586.

2. White, P. C., M. I. New, and B. Dupont. 1984. HLA-linked congenital adrenal hyperplasia results from a defective gene encoding a cytochrome P-450 specific for steroid 21-hydroxylation. Proc. Natl. Acad. Sci. USA. 81:7505-7509.

3. White, P. C., D. Grossberger, B. J. Onufer, D. D. Chaplin, M. I. New, B. Dupont, and J. L. Strominger. 1985. Two genes encoding steroid 21-hydroxylase are located near the genes encoding the fourth component of complement in man. Proc. Natl. Acad. Sci. USA. 82:1089-1094.

4. Carroll, M. C., R. D. Campbell, and R. R. Porter. 1985. The mapping of 21-hydroxylase genes adjacent to complement component 
C4 genes in HLA, the major histocompatibility complex in man. Proc. Natl. Acad. Sci. USA. 82:521-525.

5. Higashi, Y., H. Yoshioka, M. Yamane, O. Gotoh, and Y. FujiiKuriyama. 1986. Complete nucleotide sequence of two steroid 21-hydroxylase genes tandemly arranged in human chromosome: a pseudogene and a genuine gene. Proc. Natl. Acad. Sci. USA. 83:2841-2845.

6. White, P. C., M. I. New, and B. Dupont. 1986. Structure of human steroid 21-hydroxylase genes. Proc. Natl. Acad. Sci. USA. 83:5111-5115.

7. Werkmeister, J. W., M. I. New, B. Dupont, and P. C. White. 1986. Frequent deletion and duplication of the steroid 21-hydroxylase genes. Am. J. Hum. Genet. 39:461-469.

8. Rumsby, G., M. C. Carroll, R. R. Porter, D. B. Grant, and M. Hjelm. 1986. Deletion of the steroid 21-hydroxylase and complement C4 genes in congenital adrenal hyperplasia. J. Med. Genet. 23:204209.

9. Rodrigues, N. R., I. Dunham, C. Y. Yu, M. C. Carroll, R. R. Porter, and R. D. Campbell. 1987. Molecular characterization of the HLA-linked steroid 21-hydroxylase B gene from an individual with congenital adrenal hyperplasia. EMBO (Eur. Mol. Biol. Organ.) J. 6:1653-1661.

10. Amor, M., K. L. Parker, H. Globerman, M. I. New, and P. C. White. 1988. Mutation in the CYP21B gene (Ile-172 $\rightarrow$ Asn) causes steroid 21-hydroxylase deficiency. Proc. Natl. Acad. Sci. USA. 85:1600-1604

11. Wyman, A. R., and R. White. 1980. A highly polymorphic locus in human DNA. Proc. Natl. Acad. Sci. USA. 77:6754-6758.

12. Southern, E. M. 1975. Detection of specific sequences among DNA fragments separated by gel electrophoresis. J. Mol. Biol. 98:503-517.

13. Dretzen, G., P. Bellard, P. Sassone-Corsi, and P. Chambon. 1981. A reliable method for the recovery of DNA fragments from agarose and acrylamide gels. Anal. Biochem. 112:295-298.

14. Frischauf, A. M., H. Lehrach, A. Poustka, and N. Murray. 1983. Lambda replacement vectors carrying polylinker sequences. $J$. Mol. Biol. 170:827-842.

15. Hohn, B. 1979. In vitro packaging of lambda and cosmid DNA Methods Enzymol. 68:299-309.

16. Benton, W. D., and R. W. Davis. 1977. Screening lambda-gt recombinant clones by hybridization to single plaques in situ. Science (Wash. DC). 196:180-182.

17. Davis, R. W., D. Botstein, and J. R. Roth. 1980. Advanced Bacterial Genetics. Cold Spring Harbor Laboratory Publications, Cold Spring Harbor, NY. 70-116.

18. Messing, J. 1983. New M13 vectors for cloning. Methods Enzymol. 101:20-78.

19. Sanger, F., S. Nicklen, and A. R. Coulson. 1977. DNA sequencing with chain-terminating inhibitors. Proc. Natl. Acad. Sci. USA. 74:5463-5467.

20. Biggin, M. D., T. J. Gibson, and G. F. Hong. 1983. Buffer gradient gels and ${ }^{35} \mathrm{~S}$ label as an aid to rapid DNA sequence determination. Proc. Natl. Acad. Sci. USA. 80:3963-3965.

21. Kidd, V. J., R. B. Wallace, K. Itakura, and S. L. C. Woo. 1983. Alpha 1-antitrypsin deficiency detection by direct analysis of the mutation in the gene. Nature (Lond.). 304:230-234.

22. Wood, W. I., J. Gitschier, L. A. Lasky, and R. M. Lawn. 1985.
Base composition-independent hybridization in tetramethylammonium chloride: a method for oligonucleotide screening of highly complex gene libraries. Proc. Natl. Acad. Sci. USA. 82:1585-1588.

23. DiLella, A. G., J. Marvit, A. S. Lidsky, F. Gottler, and S. L. C. Woo. 1986. Tight linkage between a splicing mutation and a specific DNA haplotype in phenylketonuria. Nature (Lond.). 322:799-803.

24. Parker, K. L., D. D. Chaplin, M. Wong, J. G. Seidman, J. A. Smith, and B. P. Schimmer. 1985. Expression of murine 21-hydroxylase in mouse adrenal glands and in transfected Y1 adrenocortical tumor cells. Proc. Natl. Acad. Sci. USA. 82:7860-7864.

25. Krieg, P. A., and D. A. Melton. 1987. In vitro RNA synthesis with SP6 RNA polymerase. Methods Enzymol. 155:397-415.

26. Chirgwin, J. M., A. E. Przybyla, R. J. MacDonald, and W. J. Rutter. 1979. Isolation of biologically active ribonucleic acid from sources enriched in ribonuclease. Biochemistry. 18:5294-5299.

27. Stoner, E., J. Dimartino-Nardi, U. Kuhnle, L. S. Levine, S. E. Oberfield, and M. I. New. 1986. Is salt wasting in congenital adrenal hyperplasia due to the same gene as the fasciculata defect? Clin. Endocrinol. 24:9-20.

28. Chaplin, D. D., L. J. Galbraith, J. G. Seidman, P. C. White, and K. L. Parker. 1986. Nucleotide sequence analysis of murine 21-hydroxylase genes: mutations affecting gene expression. Proc. Natl. Acad. Sci. USA. 83:9601-9605.

29. Yoshioka, H., K. Morohashi, K. Sogawa, M. Yamane, S. Kominami, S. Takemori, Y. Okada, T. Omura, and Y. Fujii-Kuriyama. 1986. Structural analysis of cloned cDNA for mRNA of microsomal cytochrome P-450 (C21) which catalyzes steroid 21-hydroxylation in bovine adrenal cortex. J. Biol. Chem. 261:4106-4109.

30. Speiser, P. W., M. I. New, and P. C. White. 1988. Molecular genetic analysis of nonclassic steroid 21-hydroxylase deficiency associated with HLA-B14; DR1. N. Engl. J. Med. In press.

31. Chang, J. C., and Y. W. Kan. 1979. $\beta$ thalassemia, a nonsense mutation in man. Proc. Natl. Acad. Sci. USA. 76:2886-2889.

32. White, P. C., D. D. Chaplin, J. H. Weis, B. Dupont, M. I. New, and J. G. Seidman. 1984. Two steroid 21-hydroxylase genes are located in the murine $S$ region. Nature (Lond.). 312:465-467.

33. Chung, B., K. J. Matteson, and W. L. Miller. 1985. Cloning and characterization of the bovine gene for steroid 21-hydroxylase (P450c21). DNA (NY). 4:211-219.

34. Atchison, M., and M. Adesnik. 1986. Gene conversion in a cytochrome P-450 gene family. Proc. Natl. Acad. Sci. USA. 83:23002304.

35. Pang, S., M. S. Pollack, M. Loo, O. Green, R. Nussbaum, G. Clayton, B. Dupont, and M. I. New. 1985. Pitfalls of prenatal diagnosis of 21-hydroxylase deficiency congenital adrenal hyperplasia. J. Clin. Endocrinol. \& Metab. 61:89-97.

36. Mornet, E., J. Boue, M. Raux-Demay, P. Couillin, J. F. Oury, Y. Dumez, J. Dausset, D. Cohen, and A. Boue. 1986. First trimester prenatal diagnosis of 21-hydroxylase deficiency by linkage analysis to HLA-DNA probes and by 17-hydroxyprogesterone determination. Hum. Genet. 73:358-364.

37. Evans, M. I., G. P. Chrousos, D. W. Mann, J. W. Larsen, I. Green, J. McCluskey, D. L. Loriaux, J. C. Fletcher, G. Koons, J. Overpeck, and J. D. Schulman. 1985. Pharmacologic suppression of the fetal adrenal gland in utero: attempted prevention of abnormal external genital masculinization in suspected congenital adrenal hyperplasia. J. Am. Med. Assoc. 253:1015-1020. 